\title{
Advanced glaucoma at diagnosis: current perspectives
}

\author{
Alan Kastner ${ }^{1,2} \cdot$ Anthony J. King $\mathbb{D}^{1}$ \\ Received: 25 June 2019 / Revised: 8 September 2019 / Accepted: 11 September 2019 / Published online: 18 November 2019 \\ (c) The Author(s), under exclusive licence to The Royal College of Ophthalmologists 2019
}

\begin{abstract}
Presentation with advanced glaucoma is a significant risk factor for lifetime blindness. The asymptomatic nature of glaucoma, particularly in early disease, means that substantial vision loss in one eye does not always translate into a perceptible loss of visual function. This, along with the lack of an effective screening strategy, contributes to late presentation. Those most at risk of presenting with advanced glaucoma have asymptomatic high intraocular pressure (IOP), no family history of glaucoma, are socially disadvantaged, and do not attend sight testing. Patients with glaucoma may have impaired functionality for daily activities, such as reading, walking and driving. Quality of life measures have shown this to be significantly worse in patients with more severe visual field loss, particularly if bilateral. In addition, quality of life decreases faster with further bilateral visual field loss when advanced visual field damage is present. Management of these patients requires disproportionally more resources than those with earlier disease. Both medical and surgical options are used as the initial approach to treat patients presenting with advanced glaucoma. The most recently published National Institute for Health and Care Excellence (NICE) guidelines suggest that patients presenting with advanced disease should be offered trabeculectomy as a primary intervention. However, more evidence is required to determine the best initial management. The Treatment of Advanced Glaucoma Study (TAGS) is being conducted, comparing primary medical management with primary mitomycin C-augmented trabeculectomy for people presenting with advanced open-angle glaucoma. The results of TAGS will provide robust evidence for the most appropriate initial intervention.
\end{abstract}

\section{Introduction}

Glaucoma is a common, chronic, irreversible, pressurerelated optic neuropathy affecting peripheral vision in predominantly older adults [1]. Primary open-angle glaucoma (POAG) affects over $2 \%$ of those over 40 years, rising to $4 \%$ of white and $15 \%$ of black populations by the age of 80 [2]. In the UK, glaucoma affects over half a million individuals; [3] the incidence of POAG is estimated at 11,000 per year in people aged 40-70 [1,4] and there are over 1 million glaucoma-related NHS visits annually [1].

Management of glaucoma patients constitutes a significant part of ophthalmologists' workload accounting for $23 \%$ of all follow-up attendances to the UK hospital eye service [5] and $13 \%$ of all new referrals [6]. The number of patients with glaucoma is predicted to

Anthony J. King

anthony.king@nottingham.ac.uk

1 Nottingham University Hospital, Nottingham, England

2 Pontificia Universidad Católica de Chile, Santiago, Chile increase substantially as the result of an ageing population [7]. Patients with advanced glaucoma require disproportionality more clinic visits and interventions than those with early disease [8].

\section{Defining advanced glaucoma}

Ideally, for clinical management, one should be able to detect and quantify disease progression in small steps rather than identifying only the transition from one stage to the next [9]. Nevertheless, categorising the severity of glaucoma into stages has several benefits, particularly for reporting scientific studies, the economic cost of illness and the impact on quality of life (QoL).

An International Classification of Disease (ICD) and Health-Related Problems staging system exists [10]. This Glaucoma Staging Codes (GSC) categorisation considers glaucoma to be advanced if there is evidence of glaucomatous optic disc and visual field (VF) loss in both upper and lower hemifields and/or a defect encroaching within $5^{\circ}$ of fixation. As Parekh demonstrated, this ICD-9 GSC showed a significant relationship between worsening VF 
indices and RNFL loss with increasing disease severity in patients with POAG [11].

There have been many attempts to classify the extent of visual field loss $[12,13]$ and these generally include a severe or advanced category. However, there is currently no consensus agreement for defining what constitutes advanced glaucoma. Most current grading systems rely on standard automated perimetry using a 30-2 or 24-2 strategy to define severity once measurable functional loss exists [14].

The staging system most frequently used in glaucoma clinical trials [13] is the Hodapp-Parrish-Anderson (HPA) Glaucoma classification [15], which classifies damage based on two criteria: the first criterion considers the overall extent of damage, which is calculated by using both the mean deviation (MD) value and the number of defective points in the Humphrey Statpac-2 pattern deviation probability map of the 30-2 full threshold test; the second criterion is based on the defect proximity to the fixation point. The advanced loss category of the HPA (severe defect) encompasses four patterns of visual field loss. (Table 1). Examples of visual fields fulfilling the severe loss category for HPA are shown in Fig. 1.

In the recent literature, a cut-off of worse than $-12 \mathrm{~dB}$ of MD on humphrey VF testing $[16,17]$ has been considered to be advanced glaucoma and this appears to be based on the HPA Classification of Glaucoma Severity [15], which has been adopted to define advanced glaucoma and determine the effect of interventions in advanced disease [1821]. Subsequently, the National Institute for Health Care and Excellence (NICE) have adopted the Hodapp Classification for this purpose [1].

\section{Epidemiology and magnitude of the problem}

Glaucoma patients are often unaware of their condition because it is typically asymptomatic in the early stages. As a consequence, a late presentation with advanced glaucomatous damage is not uncommon.

The Early Manifest Glaucoma Trial, a landmark population-based study, performed a glaucoma screening evaluation to 32,918 patients between the ages of 55 and 79 years living in Malmö, Sweden. A total of 406 subjects $(1.23 \%)$ were identified with previously undetected glaucoma. Among them, 134 subjects (33\%) had advanced VF loss ( $>-12 \mathrm{~dB} \mathrm{MD})$ in at least one eye, and 14 were unilaterally blind due to glaucoma [22]. Baseline data from the Collaborative Initial Glaucoma Treatment Study (CIGTS), a randomised clinical trial of 607 patients with newly diagnosed open-angle glaucoma (OAG), show that $15 \%$ of subjects had a substantial VF deficit at diagnosis (VF score 10 or worse on a $0-20$ scale) [23].
Table 1 Criteria for classification of severity of glaucoma stage in the H-P-A grading system

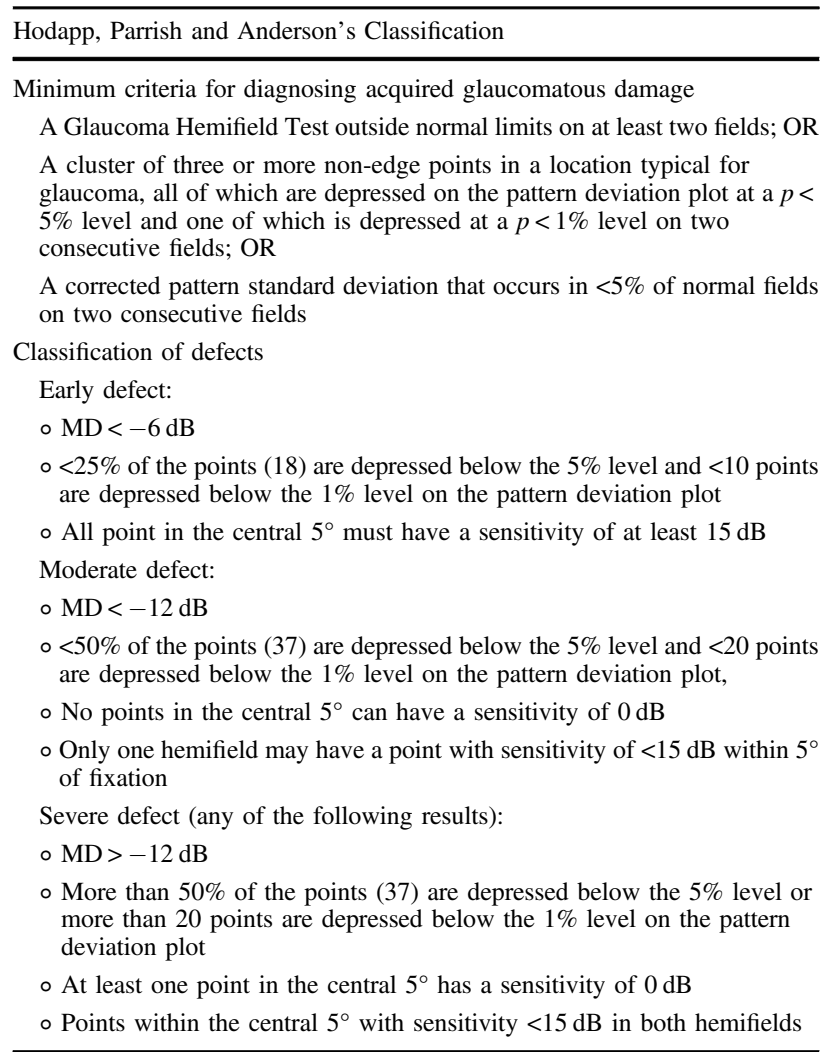

Reproduced with permission from Brusini and Johnson [13]

A study in a rural area of China that screened 5197 subjects 40 years or older reported a standardised prevalence of POAG of $1.41 \%$ or 73 cases, of whom only three had been previously diagnosed. Among undetected cases, eight were unilaterally blind as a result of POAG [24]. In a screening of 1399 subjects over 30 years old in southern India, 25 out of 27 were previously undiagnosed POAG cases with 14 being categorised as having severe damage based on a combination of an enlarged C/D ratio and VF defect (>-12 dB MD) [25]. In the UK, the most recent estimate (2006) indicates that 39\% of newly diagnosed glaucoma cases had advanced field damage in at least one eye [16]. Other estimates suggest that one in four patients present with advanced glaucoma; $[16,17,26-29]$ and electronic secondary care data from 25,000 patients (examined between 1999 and 2012 in England) showed that 21 to $30 \%$ presented with severe VF loss [17] and that although the incidence of advanced glaucoma at presentation has reduced, this reduction is slow. The ongoing Treatment of Advanced Glaucoma Study (TAGS) [21] has identified more than 900 newly diagnosed advanced glaucoma patients over 36 months in 27 centres. 


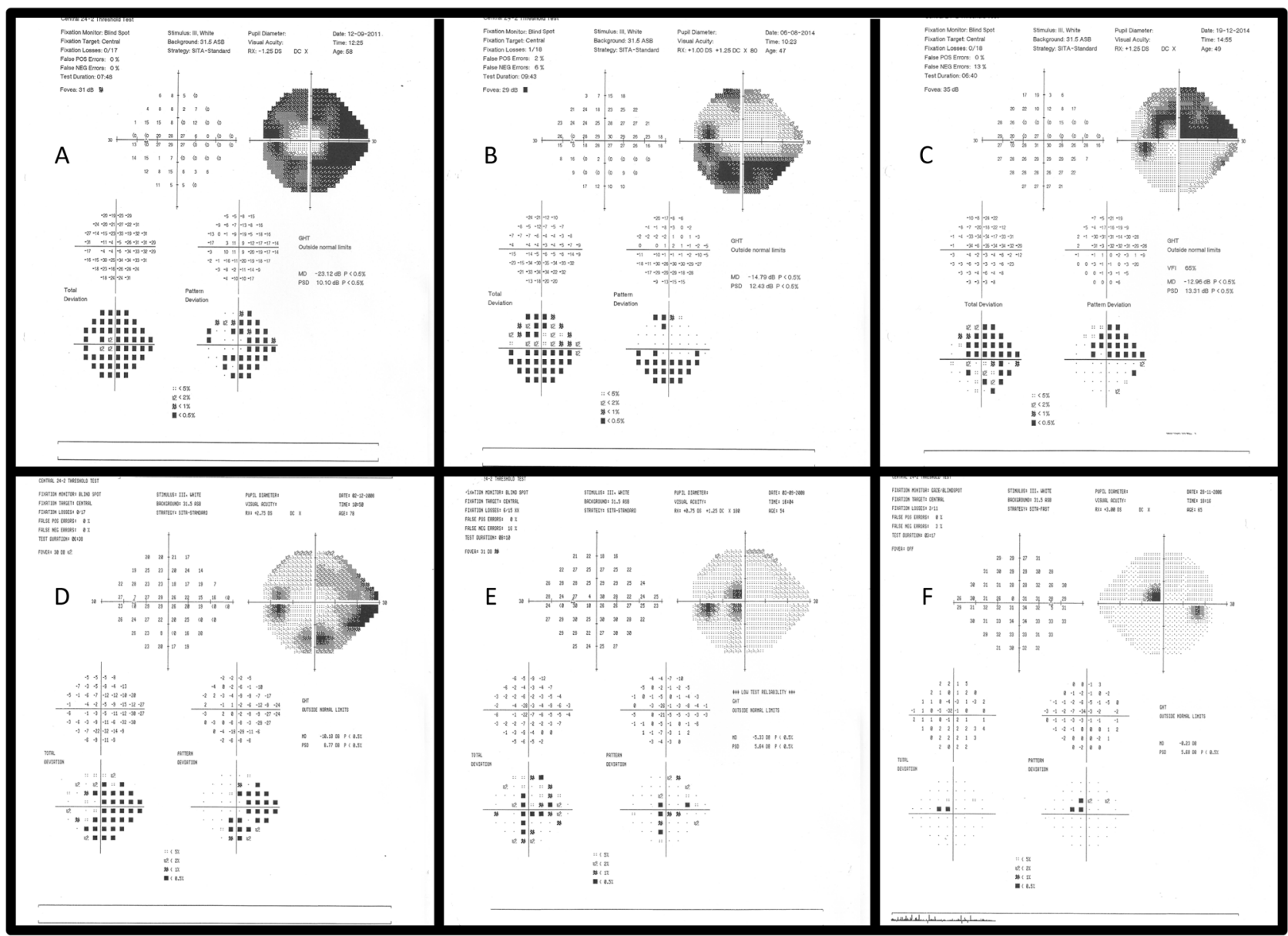

Fig. 1 Visual fields satisfying criteria for severe defect using the H-PA classification system and the criteria they meet to be classified in this category. a Mean deviation and pattern deviation plot; b pattern

\section{Risk factors for presentation with advanced glaucoma}

Currently, no effective screening strategy exists in the UK to identify all patients with glaucoma early [4]. The current recommendation of the UK National Screening Committee is not to introduce a systematic population screening and therefore, population screening for glaucoma is not currently recommended [30].

In the UK, diagnosis of glaucoma typically occurs opportunistically during routine visits to community optometrists. As glaucoma is often asymptomatic, especially if affecting one eye only, patients may not be aware they have a problem. Presentation with advanced disease may, therefore, occur because the patients are asymptomatic, or may avoid sight testing for a variety of other reasons (i.e. economic cost, access to services, health beliefs) [31]. Those most at risk of presenting with advanced glaucoma have asymptomatic high intraocular pressure (IOP), no family history of glaucoma, are socially disadvantaged and do not attend sight testing [16, 28, 32, 33]. deviation plot; c points with $0 \mathrm{~dB}$ sensitivity in the central $5^{\circ}$; d pattern deviation plot; e points with a sensitivity of $<15 \mathrm{~dB}$ in both hemifields; f points with $0 \mathrm{~dB}$ sensitivity in the central $5^{\circ}$

There is limited awareness of eye health in the UK [34-36] with the most common perception that eye health simply correlates to having good or bad sight [35], not recognising the symptoms of other eye conditions [34-38] and accepting worsening vision as a sign of ageing [34, 39]. The availability of 'ready readers', and the cost of eye tests and spectacles $[34,37,38]$ may discourage some from attending an eye test, thus delaying further the opportunity for a diagnosis of glaucoma. There are apparent sociodemographic factors that influence access to eye examinations. Older people, those on low incomes, and those living in deprived areas are least likely to access optometry care [36, 40, 41]. Sommer et al. reported racial disparities in the frequency of blindness caused by POAG in a communitybased study. Black subjects were blind in one or both eyes 10 years earlier and were 6.6 times more likely to be blind due to POAG than white subjects [42].

In addition to patient-centred causes for late detection of glaucoma, Prior [31] used qualitative techniques to explore patients' reasons for late presentation and found that missed diagnosis by optometrists, referrals to the wrong service 
such as cataract clinics and delays in referral to the hospital eye service contributed to advanced disease presentation.

\section{Quality of life and (advanced) glaucoma}

Patients are most concerned about maintaining their current level of function and QoL from the treatment of their glaucoma [43]. In recent years increasing emphasis has been placed on the patient perspective and experience of their disease, and there has been a transition from the sole use of traditional outcome metrics (e.g. VF loss, IOP) towards inclusion of patient-significant variables, such as QoL, symptoms and convenience of treatment [44].

Glaucoma damage has a substantial and detrimental effect on many aspects of daily living [45]. Balance [46-51], mobility and walking are affected, resulting in slower walking speeds and more stumbling and bumping into objects [52-54]. Glaucoma increases the risk of falls [55-63] most of which tend to occur in or close to home [64] and lead to an increased risk of fractures in glaucoma sufferers [59, 61, 65]. Driving ability is also impaired. Glaucoma patients are more likely to experience traffic accidents [66-70]. Furthermore, due to either local regulations or self-imposed restriction, they are more likely to stop driving [71-73]. Loss of driving license is a particular concern for glaucoma patients [74]. Those that continue to drive are less likely to drive at night or in the rain [71].

Patients with glaucoma read slower and find reading more difficult, which restricts this activity [75, 76]. Also, they have more difficulty with facial recognition [77].

Patients suffering from glaucoma have an increased prevalence of anxiety and depression [78-84], which may be a consequence of these daily living daily restrictions impacting negatively on independence and social functioning. In one study, glaucoma patients were shown to be 10.6 and 12.3 times more likely to have depression and anxiety symptoms, respectively [78].

In the context of more severe glaucoma, the presence of more advanced VF loss has been shown to influence the reduction of walking speeds $[47,53,54]$ and increase the risk of falling $[57,59,85]$ compared with those with less severe disease. Similarly, those with more severe glaucoma experienced a higher percentage of fractures (of any type) after a fall than those with mild and moderate damage [64].

Patients with more severe glaucoma had a higher risk of at-fault motor vehicle collision [68], and the severity of VF loss increased the odds of either regulatory or voluntary driving cessation [71].

Using traditional grading systems to define advanced glaucomatous vision loss usually refers to VF loss in an eye (uniocular). However, vision-related QoL is a binocular phenomenon. Therefore, the effects on QoL from advanced glaucoma vary depending upon the relative amount of VF loss in each eye and are greatly affected by the level of VF loss in the less damaged eye [86-88] (Fig. 2).

QoL can be assessed using health-related QoL outcome tools, and a large number of these have been applied to measure QoL in patients with glaucoma [89-92]. Generic (e.g. Health Utilities Index, EuroQoL Instrument 'EQ-5D'), vision specific (e.g. 'NEI VFQ-25') and glaucoma specific (e.g. Glaucoma QoL-15 and Glaucoma Profile Index) tools have all been used to evaluate the relationship between QoL and vision loss due to glaucoma.

Vision and glaucoma specific instruments appear to have a better correlation to glaucoma VF loss than generic instruments [87, 88].

QoL is worse in patients with more severe VF loss [86$88,93,94]$. Gutierrez demonstrated that QoL is most related to the level of VF loss in the better eye [88]. McKeanCowdin found an approximately linear relationship between VF damage (i.e. worse MD), and NEI VFQ-25 composite scores in both the better and the worse seeing eye. The former had a larger $\beta$ coefficient suggesting that QoL score decreases more as a result of deterioration of $\mathrm{VF}$ in the better seeing eye (Fig. 3) [86]. Medeiros correlated the loss of mean sensitivity (MS) of the integrated binocular VF with a reduction of QoL. He demonstrated that for subjects with more severe disease at baseline, changes in binocular field sensitivity produced significantly larger changes in NEI VFQ-25 scores compared with subjects with less severe disease at baseline [94] (Fig. 4).

Abe explored how sensitivity loss across different regions of the VF impacts on loss of QoL. He determined that progressive decline in sensitivity in the central inferior region of the VF has the strongest association with decline in QoL. For this area, each $1 \mathrm{~dB}$ lower MS at baseline was associated with a 0.15 -unit/year greater decline in NEI VFQ-25 scores [95].

\section{Advanced glaucoma at presentation-a risk factor for blindness}

Severe VF loss at diagnosis is a risk factor for progressive severe visual deterioration. Odberg [96] noted in a cohort of patients with advanced glaucoma that $70 \%$ of the affected eyes had progressed after a mean of 7.6 years despite being treated. Grant and Burke [97] found that eyes with a VF defect at the beginning of treatment were more likely to progress to blindness than eyes in which treatment was started when there was no field loss. Wilson [98] found that initial field loss was the strongest determinant of the rate of further field loss. The rate of deterioration was 11.7 times 


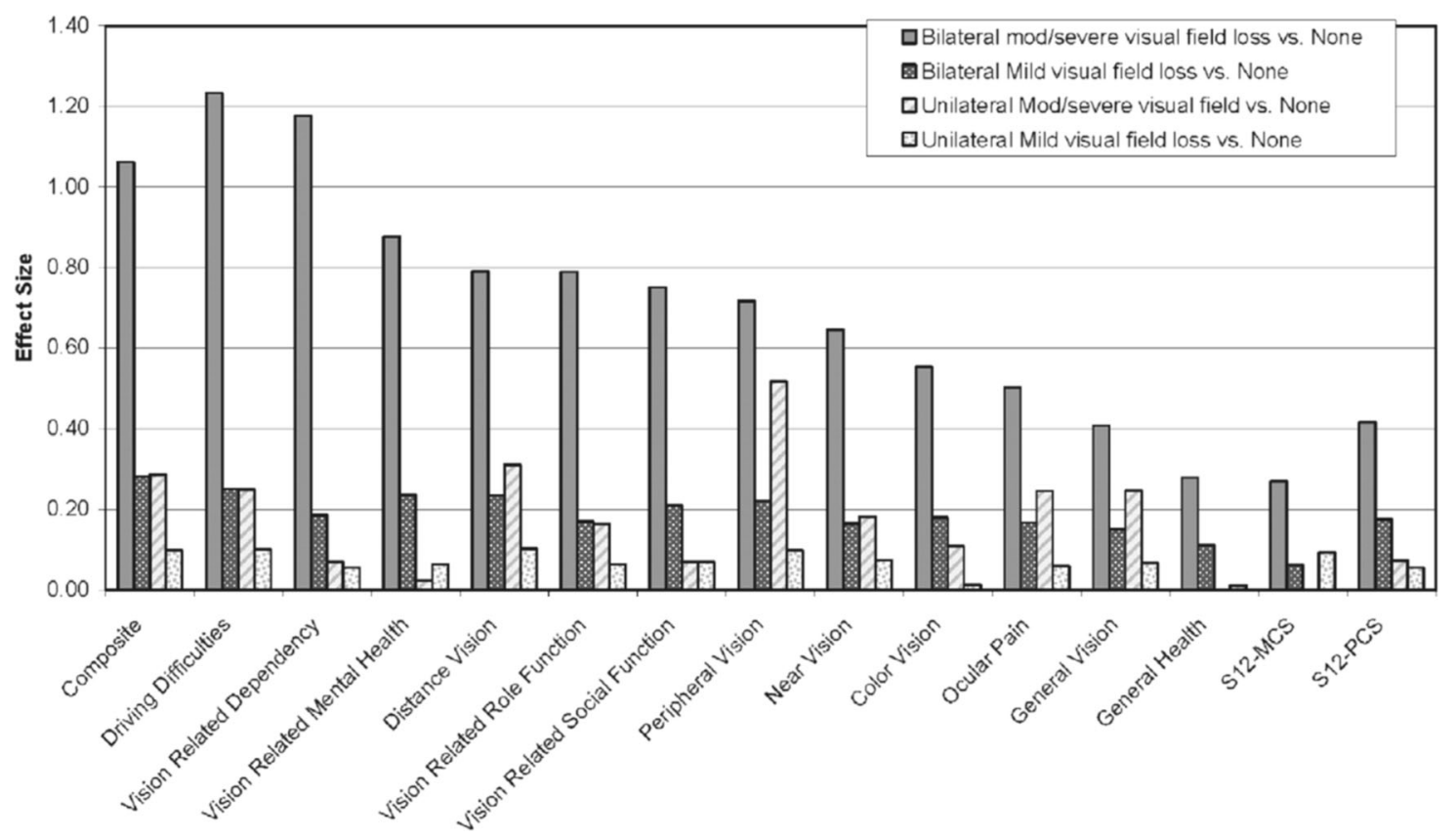

Fig. 2 Comparison of effect sizes (ES)s between the no visual field loss (VFL) subgroup with subgroups with different severity levels of VFL. The level of VFL was stratified into five categories: no VFL (mean deviation $[\mathrm{MD}]>-2$ decibels $[\mathrm{dB}]$ in both eyes), unilateral mild VFL $(-6 \mathrm{~dB}<\mathrm{MD}<-2 \mathrm{~dB}$ in the worse eye), unilateral moderate to severe VFL $(\mathrm{MD}<-6 \mathrm{~dB}$ in one eye, $\mathrm{MD}>-2 \mathrm{~dB}$ in the other eye), bilateral mild VFL ( $-6 \mathrm{~dB}<\mathrm{MD}<-2 \mathrm{~dB}$ in both eyes; or -6 $\mathrm{dB}<\mathrm{MD}<-2 \mathrm{~dB}$ in one eye, $\mathrm{MD}<-6 \mathrm{~dB}$ in the other eye), and bilateral moderate to severe VFL (MD $<-6 \mathrm{~dB}$ in both eyes). The ES was calculated as the difference in the adjusted mean scores (between each of the severity level of VFL and no VFL) divided by the standard deviation for the no VFL group. Subscales are clustered in decreasing order of ESs for the bilateral moderate to severe VFL vs none groups, for the 25-item National Eye Institute Visual Function Questionnaire (NEI-VFQ-25) vision-related subscales, and the Medical Outcomes Study 12-item Short-Form Health Survey (SF-12) general health subscale scores. ESs below 0.20 represent no statistically significant effect. An ES of 0.20 to 0.49 is considered to be a small effect, 0.50 to 0.79 a medium effect, and 0.80 or more a large effect. Reproduced with permission from McKean-Cowdin et al. [86] faster in eyes with more advanced field loss at presentation. Mikelberg [99] found that when scotoma mass was small (i.e. early glaucoma) the rate of VF loss was slow, but when large (i.e. severe glaucoma), rapid linear progression of VF loss occurred. This observation was confirmed by Lee, who identified risk factors for rapid progression of the disease. Patients with more severe glaucomatous damage, as measured by VF or optic disc cupping are at highest risk for rapid worsening of the disease [100]. Oliver found that unilateral blindness due to glaucoma at presentation more than doubled the risk of bilateral blindness [101].

Several studies using different methodologies have concluded that severe VF loss at diagnosis is the greatest risk factor for lifetime blindness [20, 102-105]. Mokhales et al. specifically explored the risk of treated glaucoma patients becoming blind in their lifetime [102, 106]. In their systematic review, they identified five studies reporting end of life visual impairment [20, 103, 104, 107, 108]. Three identified advanced disease at diagnosis as a risk factor for blindness [20, 104, 107]. Peters [20] using a six-scale grading system demonstrated that those presenting with advanced disease were at highest risk of lifetime blindness and found that the risk of blindness increased with each stage of more advanced field loss at the time of diagnosis (OR 1.80 95\% CI 1.34-2.41) (Fig. 5).

In addition to glaucoma itself being a risk factor for blindness, there is evidence that having glaucoma increases the risk of having other potentially blinding conditions. In a recent review of a glaucoma clinic cohort [109], 14.8\% of patients had retinal comorbidity. Patients with comorbid retinal disease had a higher prevalence of blindness and low vision than those without comorbid retinal disease $(1.97 \%$ versus $1.02 \%, P=0.02)$. There is an increased risk of retinal vascular occlusions occurring in those suffering from glaucoma [110, 111]. In a recent meta-analysis it was shown that glaucoma was associated with central retinal vein occlusion (OR: 6.21; 95\% CI: 4.64-8.31), branch retinal vein occlusion (OR: 2.38; 95\% CI: 1.77-3.19) and hemiretinal vein occlusion (OR: 4.60; 95\% CI: 2.26-9.35), demonstrating a considerable risk of blindness from these vascular conditions. Prevention of glaucoma blindness minimises its contribution to mixed pathology blindness, thus reducing the risk blindness beyond that due to glaucoma alone. 


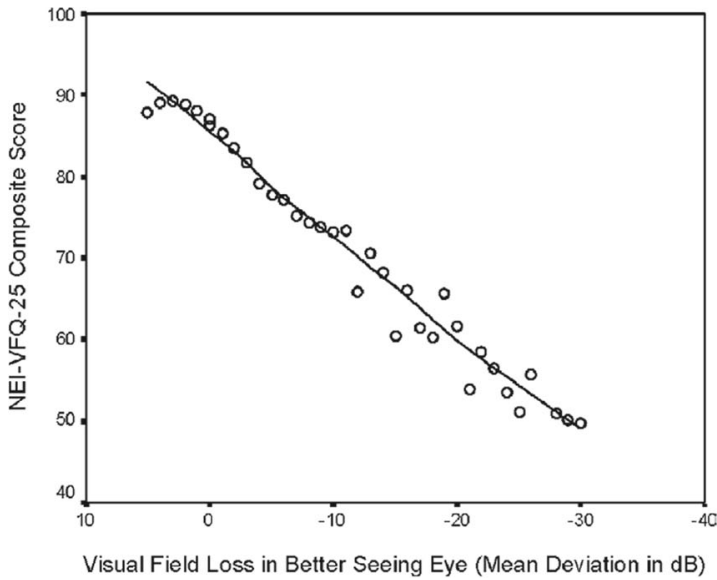

Fig. 3 Locally weighted least square (LOWESS) plot of National Eye Institute Visual Function Questionnaire (NEI-VFQ-25) composite scores and visual field loss (VFL) (mean deviation [MD] scores in decibels) in the better-seeing eye. The NEI-VFQ-25 composite scores are adjusted for covariates including age, gender, education, employment status, income, acculturation, comorbidities, health insurance, vision insurance, and visual acuity (VA) impairment. The MD-specific data of all persons by each unit of MD of VFL were plotted to show the independent relationship of VFL with vision-specific quality of life. Locally weighted least square (LOWESS) plot of 25-item

\section{Treatment options}

Glaucoma requires lifelong care. The estimated mean age of death following diagnosis is 80.5 years [112]. Time from diagnosis to death varies from 7.4 to 12.4 years [103, 108, 112-114]. An ageing population living longer means that the number needing treatment will increase and will need treatment for a longer period of time. At death, $42.2 \%$ are unilaterally blind from glaucoma and $16.4 \%$ bilaterally blind for a mean duration of 2 years prior to death [114]. This number is likely to increase as people live longer.

Treatment options for glaucoma are effective, and early detection delays disease progression. In turn, although irreversible, glaucoma sight loss and blindness are preventable when the disease is identified early and is appropriately treated [115-117]. Reducing IOP is currently the only effective treatment to prevent glaucoma progression $[116,118-120]$. Better IOP control at an early stage reduces the risk of progression to blindness [116]. The Advanced Glaucoma Intervention Study (AGIS) demonstrated that the extent of IOP lowering was related to the progression of VFs over an 8-year period showing that progression was least when IOPs were maintained below $18 \mathrm{mmHg}$ at all follow-up visits [116]. This study also suggested that the probability of VF stabilisation was increased in patients who had early IOPs below $14 \mathrm{mmHg}$. This finding has been used to justify aggressive IOP lowering in advanced glaucoma (i.e. to below $14 \mathrm{mmHg}$ ).

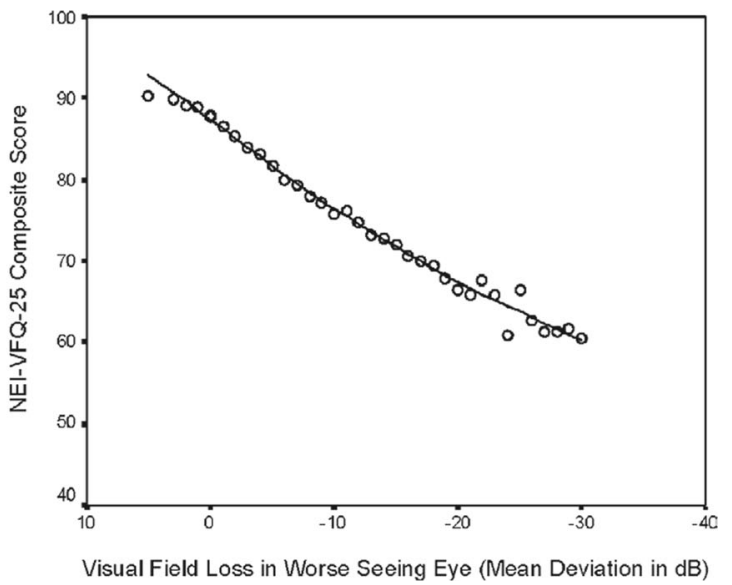

National Eye Institute Visual Function Questionnaire (NEI-VFQ-25) composite scores and visual field loss (VFL) (mean deviation [MD] scores in decibels) in worse-seeing eye. The NEI-VFQ-25 composite scores are adjusted for covariates including age, gender, education, employment status, income, acculturation, comorbidities, health insurance, vision insurance, and visual acuity (VA) impairment. The MD-specific data of all persons by each unit of MD of VFL were plotted to show the independent relationship of VFL with visionspecific quality of life. Reproduced with permission from McKeanCowdin et al. [86]

\section{Existing evidence for treatment of advanced glaucoma}

Although a study of advanced glaucoma, the AGIS has already been undertaken this trial defined advanced glaucoma as 'When maximum effective, accepted and tolerated medications fail to reduce IOP adequately and there has been some VF loss' [121, 122]. However, AGIS did establish in its associative analysis that those patients who maintained an IOP of $<18 \mathrm{mmHg}$ in the following 6 years had virtually no VF progression, and the mean IOP of this group was $12.3 \mathrm{mmHg}$, therefore suggesting that a mean of $12 \mathrm{mmHg}$ should be sufficient to prevent further VF loss. This is an important consideration for those with advanced VF loss. The Tube Versus Trabeculectomy (TVT) study [123] recruited subjects with previous surgical intervention and a mean defect of -16.7 (9.32), however, TVT study, such as AGIS, represent a group of patients who have had previous medical and/or surgical interventions and are not reflective or primary interventions or newly diagnosed glaucoma. However, TVT did suggest that at 5 years 53\% of the trabeculectomy group and $70 \%$ of the tube group maintained an IOP $<14 \mathrm{mmHg}$. The Primary Tube Versus Trabeculectomy Study (PTVT) included subjects with medically uncontrolled glaucoma but no previous incisional ocular surgery. It had a mean MD of -14.6 for subjects. PTVT showed that at 12 months the cumulative failure rate for maintaining IOP $<14 \mathrm{mmHg}$ was $28.1 \%$ and $20 \%$, respectively, for the tube and trabeculectomy groups [124]. 


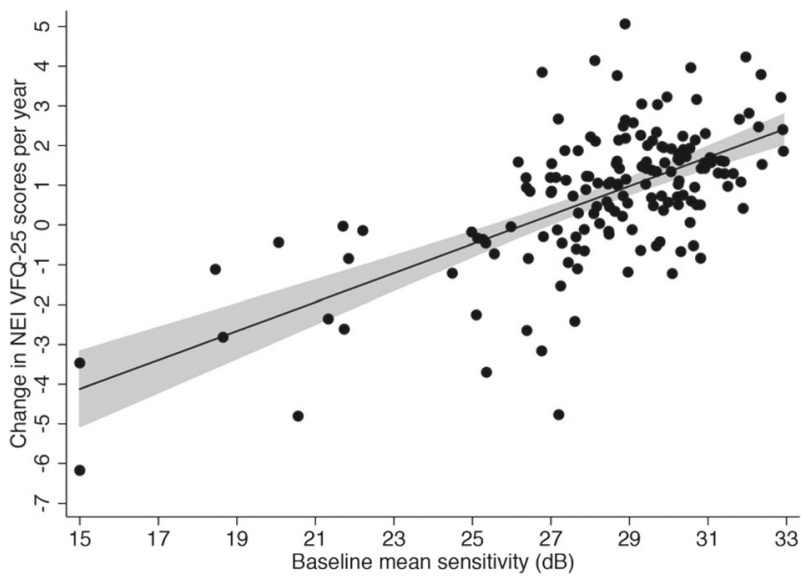

Fig. 4 Scatterplot with fitted regression line showing the relationship between change in NEI VFQ-25 scores and baseline disease severity as measured by binocular mean sensitivity. The shaded area corresponds to the $95 \%$ confidence interval of the regression slope. $\mathrm{dB}$ decibel. Reproduced with permission from Medeiros et al. [94]

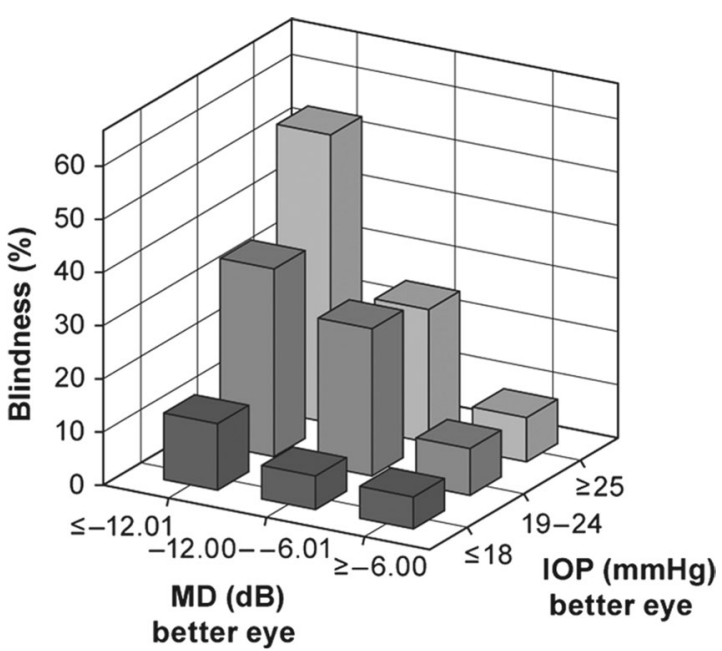

Fig. 5 Rates of glaucoma blindness for different levels of intraocular pressure and mean deviation at the time of diagnosis. MD mean deviation, dB decibel, IOP intraocular pressure. Reproduced with permission from Peters et al. [20]

Kirwan et al. [125] undertook a multicenter service evaluation and examined the success of trabeculectomy in POAG using different cut-off values for defining success. When requiring an IOP of $<15 \mathrm{mmHg}$ or a reduction in at least $40 \%$ from baseline, the overall success of trabeculectomy was $64 \%$ at 2 years.

Several other smaller studies have specifically looked at surgical intervention to prevent further VF loss in patients with advanced glaucoma. Stead [126] explored the value of trabeculectomy in 103 eyes with an $\mathrm{MD}<-20 \mathrm{~dB}$ and found a qualified success rate of $85 \%$ at 3 years for an IOP $<16 \mathrm{mmHg}$. Tsagkataki [19] explored the value of viscocanalostomy and phaco-viscocanalostomy in advanced glaucoma and found a qualified success of $60 \%$ at 3 years for $\mathrm{IOP}<16 \mathrm{mmHg}$.

A recent Cochrane systematic review [127] comparing primary medical versus surgical treatment for OAG identified four relevant studies with 888 patients previously untreated for POAG. Despite methodological weaknesses and non-standard treatments [119, 128-130], the authors concluded that 'in more severe OAG there is some evidence, from three trials that medication was associated with more progressive VF loss and less IOP lowering than surgery. Risk of treatment failure was greater with medication than trabeculectomy (OR 3.90, 95\% CI 1.60-9.53; HR 7.27, 95\% CI 2.23-25.71)'. Three of these four trials are now obsolete because of new medical treatments, and the most recent study did not include patients with advanced disease. The authors concluded that surgery lowers IOP more than medication. However, none of these trials specifically addressed the management of those presenting with advanced glaucoma or used modern glaucoma medications known to produce lower IOP and have fewer side effects than previous generations of drops. The authors recommend that further RCTs comparing current medical treatments with modern glaucoma surgery are required in people with advanced OAG.

A further modelling evaluation from the CIGTS suggested that patients with more advanced glaucoma $(\mathrm{MD}<-10)$ had better VF preservation at 5 years if they had surgery as their primary intervention compared with those who received initial medication, (mean difference $0.74 \mathrm{~dB}(95 \% \mathrm{CI}-0.00$ to 1.48 ).

In the years after CIGTS completed its recruitment, there have been significant developments in surgical techniques and an expansion of medical treatment options for patients.

\section{Current practise}

In the UK, NICE provides guidance for the management of glaucoma patients. The most recently published NICE guidelines suggest patients presenting with advanced disease should be offered trabeculectomy as a primary intervention and only offered medical treatment if surgery is declined [1] but highlighted that the evidence to support this recommendation is of poor quality. The European Glaucoma Guidelines [131] indicate that primary trabeculectomy should be considered in patients presenting with advanced glaucoma and the Preferred Practice Patterns of the American Academy of Ophthalmology do not offer treatment advice specifically for those presenting with advanced glaucoma but suggest that primary trabeculectomy 'can be considered in selected cases as initial therapy' [132].

Despite this guidance currently in the UK, most ophthalmologists treat patients medically starting with topical drop monotherapy followed by escalating the number 
of drops until maximum tolerated combination therapy is achieved [133]. The primary concern of clinicians appears to be the risk of complications from trabeculectomy surgery and a lack of robust evidence supporting the use of primary surgery in advanced glaucoma [133].

One of the main concerns of clinicians is the unexplained irreversible loss of central vision-'wipe-out'-believed to occur in patients with advanced glaucoma undergoing trabeculectomy [134]. However, while visual loss is not uncommon after trabeculectomy, in the majority of cases this is reversible and explained by identifiable factors [135-138]. Two prospective studies $[137,138]$ specifically exploring the development of wipe-out found no cases of severe irreversible unexplained central vision loss, suggesting that, if wipe-out exists it is a notably infrequent event.

Despite the concerns of clinicians, patients have indicated that they are not concerned about the treatment they receive as long as it is effective in prevention of further visual loss and in maintaining their QoL $[43,74]$ and one study has suggested that QoL is equivalent for medical and surgical treatment in patients with more advanced glaucoma [139].

For patients presenting with advanced glaucoma, the challenge is to institute the treatment most likely to be effective as the initial therapy. Unlike with early disease, the facility to make multiple adjustments to treatment before severe visual loss occurs is much less (Fig. 6).

\section{Resource implications}

In contrast to early disease, late presentation with advanced glaucoma is associated with higher resource use (clinic visit frequency, medication use, laser and surgical treatment) $[8,140,141]$ and more advanced disease is more expensive to manage [142]. Late presentation is also associated with a higher risk of blindness compared with early stage detection; [20] glaucoma is the second leading cause of blind registrations [143]. Blindness and sight loss have a significant socio-economic impact in terms of public funds, private expenditure and health provision [144-147].

\section{Need for further research}

Currently, no effective screening strategy exists in the UK to identify all patients with glaucoma early in the course of the disease [4], and screening has been deemed not to be cost effective [30]. As a consequence, a large proportion of newly diagnosed glaucoma patients continue to present with advanced disease [16, 17, 26-29].
A Aim of Treatment

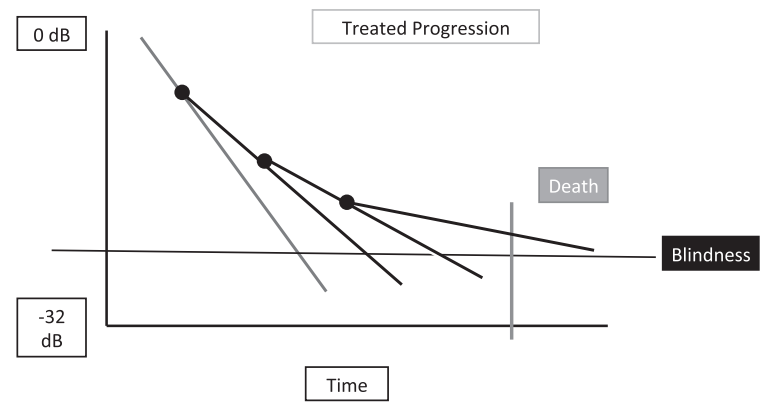

B Aim of Treatment

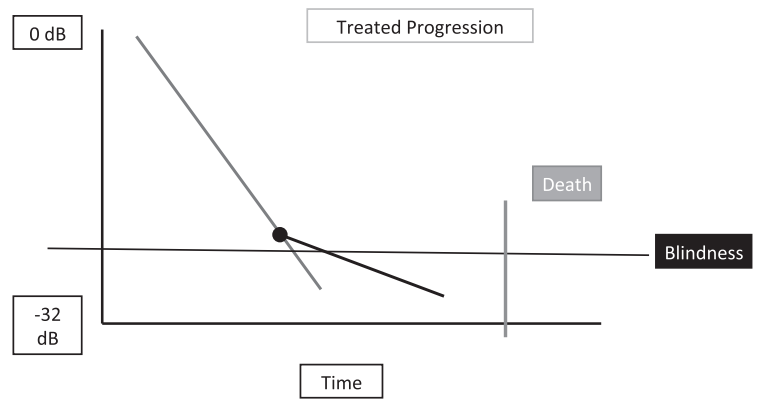

C Aim of Treatment

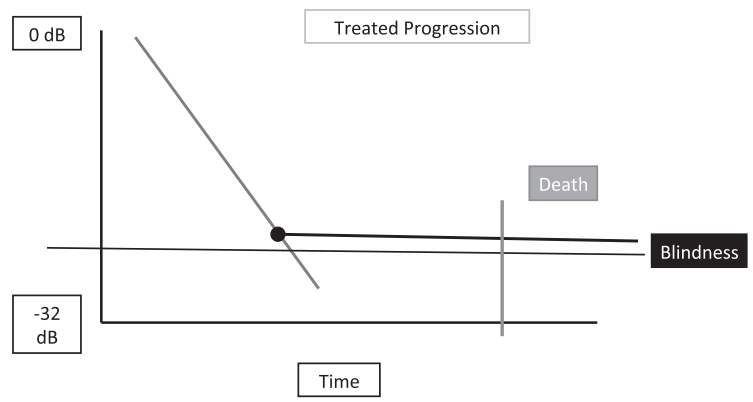

Fig. 6 a Diagnosis of glaucoma at early stage with time for multiple intervention points to adjust treatment to prevent vision loss. b Diagnosis at advanced stage with inadequate initial treatment resulting in further progression to blindness. c Diagnosis at advanced stage with adequate initial treatment preventing progression to blindness before death

Sight loss from glaucoma is preventable, and the Public Health Outcomes Framework for England 2013-2016 has made reducing numbers of people living with preventable sight loss a priority [148].

NICE guidelines currently recommend primary surgery [1], but clinicians do not commonly follow this advice because of the lack of robust evidence to support surgery [133].

Prevention of glaucoma progression is one of the top ten James Lind Alliance glaucoma priorities (http://www.jla. nihr.ac.uk/priority-setting-partnerships/sight-loss-andvision/top-10-priorities/glaucoma-top-10.htm) and a recent Cochrane review has recommended further research to 
explore the best treatment options for those presenting with advanced disease [127].

Further evidence is required to support the best initial treatment approach to patients presenting with advanced glaucoma [149]. To address the uncertainties about the best primary treatment option for patients presenting with advanced glaucoma, the TAGS is being undertaken [21].

TAGS is a pragmatic, multicentric, randomised controlled trial comparing clinical and cost-effectiveness of primary medical management compared with primary mitomycin C-augmented trabeculectomy for people presenting with advanced OAG.

The results of TAGS should provide robust evidence for clinical, QoL and cost-effectiveness to inform patients, clinicians and health care commissioners of the best option for management of newly diagnosed advanced glaucoma.

\section{Compliance with ethical standards}

Conflict of interest The authors declare that they have no conflict of interest.

Publisher's note Springer Nature remains neutral with regard to jurisdictional claims in published maps and institutional affiliations.

\section{References}

1. National Institute for Health and Care Excellence. Glaucoma diagnosis and management NICE guideline [NG81]. 2017. https://www.nice.org.uk/guidance/ng81. Accessed 01/06/2019.

2. Quigley HA, Broman AT. The number of people with glaucoma worldwide in 2010 and 2020. Br J Ophthalmol. 2006;90:262-7.

3. Minassian DC, Reidy A, Coffey M, Minassian A. Utility of predictive equations for estimating the prevalence and incidence of primary open angle glaucoma in the UK. Br J Ophthalmol. 2000;84:1159-61.

4. Burr JM, Mowatt G, Hernandez R, Siddiqui MA, Cook J, Lourenco $\mathrm{T}$, et al. The clinical effectiveness and cost-effectiveness of screening for open angle glaucoma: a systematic review and economic evaluation. Health Technol Assess. 2007;11:1190. p.iii-iv, ix-x

5. Spry PG, Spencer IC, Sparrow JM, Peters TJ, Brookes ST, Gray S, et al. The Bristol Shared Care Glaucoma Study: reliability of community optometric and hospital eye service test measures. $\mathrm{Br}$ J Ophthalmol. 1999;83:707-12.

6. Harrison RJ, Wild JM, Hobley AJ. Referral patterns to an ophthalmic outpatient clinic by general practitioners and ophthalmic opticians and the role of these professionals in screening for ocular disease. BMJ. 1988;297:1162-7.

7. Morley AM, Murdoch I. The future of glaucoma clinics. Br J Ophthalmol. 2006;90:640-5.

8. Lee PP, Walt JG, Doyle JJ, Kotak SV, Evans SJ, Budenz DL, et al. A multicenter, retrospective pilot study of resource use and costs associated with severity of disease in glaucoma. Arch Ophthalmol. 2006;124:12-9.

9. The European Glaucoma Society. Terminology and Guidelines for Glaucoma, 4th Edition - Part 1 Supported by the EGS Foundation. Br J Ophthalmol. 2017;101:1-72.
10. The World Health Organization. International Classification of Diseases, Tenth Revision, Clinical Modification (ICD-10-CM).

11. Parekh AS, Tafreshi A, Dorairaj SK, Weinreb RN. Clinical applicability of the International Classification of Disease and Related Health Problems (ICD-9) glaucoma staging codes to predict disease severity in patients with open-angle glaucoma. J Glaucoma. 2014;23:e18-22.

12. Ng M, Sample PA, Pascual JP, Zangwill LM, Girkin CA, Liebmann JM, et al. Comparison of visual field severity classification systems for glaucoma. J Glaucoma. 2012;21:551-61.

13. Brusini $\mathrm{P}$, Johnson CA. Staging functional damage in glaucoma: review of different classification methods. Surv Ophthalmol. 2007;52:156-79.

14. de Moraes CG, Liebmann JM, Medeiros FA, Weinreb RN. Management of advanced glaucoma: Characterization and monitoring. Surv Ophthalmol. 2016;61:597-615.

15. Hodapp E, Parrish RK, Anderson DR. Clinical decisions in glaucoma. 1993, St Louis C.V.: Mosby.

16. Ng WS, Agarwal PK, Sidiki S, McKay L, Townend J, AzuaraBlanco A. The effect of socio-economic deprivation on severity of glaucoma at presentation. Br J Ophthalmol. 2010;94:85-7.

17. Boodhna T, Crabb DP. Disease severity in newly diagnosed glaucoma patients with visual field loss: trends from more than a decade of data. Ophthalmic Physiol Opt. 2015;35:225-30.

18. Inuzuka H, Sawada A, Yamamoto T. Comparison of changes in macular ganglion cell - inner plexiform layer thickness between medically and surgically treated eyes with advanced glaucoma. Am J Ophthalmol. 2018;187:43-50.

19. Tsagkataki M, Bampouras TM, Choudhary A. Outcomes of viscocanalostomy and phaco-viscocanalostomy in patients with advanced glaucoma. Graefes Arch Clin Exp Ophthalmol. 2018;256:1481-7.

20. Peters D, Bengtsson B, Heijl A. Factors associated with lifetime risk of open-angle glaucoma blindness. Acta Ophthalmol. 2014;92:421-5.

21. King AJ, Fernie G, Azuara-Blanco A, Burr JM, Garway-Heath T, Sparrow JM, et al. Treatment of Advanced Glaucoma Study: A multicentre randomised controlled trial comparing primary medical treatment with primary trabeculectomy for people with newly diagnosed advanced glaucoma - Study protocol. British Journal of Ophthalmology. 2018;102:922-8.

22. Heijl A, Bengtsson B, Oskarsdottir SE. Prevalence and severity of undetected manifest glaucoma: results from the early manifest glaucoma trial screening. Ophthalmology. 2013; 120:1541-5.

23. Gillespie BW, Musch DC, Guire KE, Mills RP, Lichter PR, Janz NK, et al. The collaborative initial glaucoma treatment study: baseline visual field and test-retest variability. Invest Ophthalmol Vis Sci. 2003;44:2613-20.

24. Song W, Shan L, Cheng F, Fan P, Zhang L, Qu W, et al. Prevalence of glaucoma in a rural northern china adult population: a population-based survey in Kailu County, inner Mongolia. Ophthalmology. 2011;118:1982-8.

25. Dandona L, Dandona R, Srinivas M, Mandal P, John RK, McCarty CA, et al. Open-angle glaucoma in an urban population in southern India: the Andhra Pradesh eye disease study. Ophthalmology. 2000;107:1702-9.

26. Coffey M, Reidy A, Wormald R, Xian WX, Wright L, Courtney $\mathrm{P}$. Prevalence of glaucoma in the west of Ireland. Br J Ophthalmol. 1993;77:17-21.

27. Sheldrick JH, Ng C, Austin DJ, Rosenthal AR. An analysis of referral routes and diagnostic accuracy in cases of suspected glaucoma. Ophthalmic Epidemiol. 1994;1:31-9.

28. Sukumar S, Spencer F, Fenerty C, Harper R, Henson D. The influence of socioeconomic and clinical factors upon the 
presenting visual field status of patients with glaucoma. Eye (Lond). 2009;23:1038-44.

29. Elkington AR, MacKean JPS. A collaborative hospital glaucoma survey. Res Clin Forums. 1982;4:31-40.

30. The UK National Screening Committee. The UK NSC recommendation on Glaucoma screening in adults. Available at https:// legacyscreening.phe.org.uk/glaucoma. 2016.

31. Prior M, Francis JJ, Azuara-Blanco A, Anand N, Burr JM. Glaucoma Screening Platform Study Group. Why do people present late with advanced glaucoma? A qualitative interview study. Br J Ophthalmol. 2013;97:1574-8.

32. Fraser S, Bunce C, Wormald R. Risk factors for late presentation in chronic glaucoma. Invest Ophthalmol Vis Sci. 1999;40: 2251-7.

33. Fraser S, Bunce C, Wormald R, Brunner E. Deprivation and late presentation of glaucoma: case-control study. BMJ. 2001;322: 639-43.

34. Shickle D, Griffin M. Why don't older adults in England go to have their eyes examined? Ophthalmic Physiol Opt. 2014;34:38-45.

35. Leamon S, Hayden C, Lee H, Trudinger D, Appelbee E, Hurrell DL, et al. Improving access to optometry services for people at risk of preventable sight loss: a qualitative study in five UK locations. J Public Health (Oxf). 2014;36:667-73.

36. McLaughlan BEA. Understanding of the purpose of an eye test among people aged 60 and over in the UK. Optometry Pract. 2010;11:179-88.

37. Awobem JF, Cassels-Brown A, Buchan JC, Hughes KA. Exploring glaucoma awareness and the utilization of primary eye care services: community perceived barriers among elderly African Caribbeans in Chapeltown, Leeds. Eye (Lond). 2009;23:243. author reply 243.

38. Cross V, Shah P, Bativala R, Spurgeon P. ReGAE 2: glaucoma awareness and the primary eye-care service: some perceptions among African Caribbeans in Birmingham UK. Eye (Lond). 2007;21:912-20.

39. Patel DBH, Murdoch I. Barriers to uptake of eye care services by the Indian population living in Ealing, West London. Health Educ J. 2006;65:267-76.

40. Shickle D, Farragher TM. Geographical inequalities in uptake of NHS-funded eye examinations: small area analysis of Leeds, UK. J Public Health (Oxf). 2015;37:337-45.

41. Burr J, Hernandez R, Ramsay C, Prior M, Campbell S, AzuaraBlanco A, et al. Is it worthwhile to conduct a randomized controlled trial of glaucoma screening in the United Kingdom? J Health Serv Res Policy. 2014;19:42-51.

42. Sommer A, Tielsch JM, Katz J, Quigley HA, Gottsch JD, Javitt JC, et al. Racial differences in the cause-specific prevalence of blindness in east Baltimore. N Engl J Med. 1991;325:1412-7.

43. Kulkarni BB, Leighton P, King AJ. Exploring patients' expectations and preferences of glaucoma surgery outcomes to facilitate healthcare delivery and inform future glaucoma research. British Journal of Ophthalmology. Published Online First: April 2019. https://doi.org/10.1136/bjophthalmol-2018-313401.

44. Braithwaite T, Calvert M, Gray A, Pesudovs K, Denniston AK. The use of patient-reported outcome research in modern ophthalmology: impact on clinical trials and routine clinical practice. Patient Relat Outcome Meas. 2019;10:9-24.

45. Sotimehin AE, Ramulu PY. Measuring Disability in Glaucoma. J Glaucoma. 2018;27:939-49.

46. Tomomitsu MS, Alonso AC, Morimoto E, Bobbio TG, Greve JM. Static and dynamic postural control in low-vision and normal-vision adults. Clinics (Sao Paulo). 2013;68:517-21.

47. Shabana N, Cornilleau-Peres V, Droulez J, Goh JC, Lee GS, Chew PT. Postural stability in primary open angle glaucoma. Clin Exp Ophthalmol. 2005;33:264-73.
48. Kotecha A, Richardson G, Chopra R, Fahy RT, Garway-Heath DF, Rubin GS. Balance control in glaucoma. Invest Ophthalmol Vis Sci. 2012;53:7795-801.

49. de Luna RA, Mihailovic A, Nguyen AM, Friedman DS, Gitlin LN, Ramulu PY. The Association of Glaucomatous Visual Field Loss and Balance. Transl Vis Sci Technol. 2017;6:8.

50. Black AA, Wood JM, Lovie-Kitchin JE, Newman BM. Visual impairment and postural sway among older adults with glaucoma. Optom Vis Sci. 2008;85:489-97.

51. Diniz-Filho A, Boer ER, Gracitelli CP, Abe RY, van Driel N, Yang Z, et al. Evaluation of Postural Control in Patients with Glaucoma Using a Virtual Reality Environment. Ophthalmology. 2015;122:1131-8.

52. Friedman DS, Freeman E, Munoz B, Jampel HD, West SK. Glaucoma and mobility performance: the Salisbury Eye Evaluation Project. Ophthalmology. 2007;114:2232-7.

53. Mihailovic A, Swenor BK, Friedman DS, West SK, Gitlin LN, Ramulu PY. Gait Implications of Visual Field Damage from Glaucoma. Transl Vis Sci Technol. 2017;6:23.

54. Turano KA, Rubin GS, Quigley HA. Mobility performance in glaucoma. Invest Ophthalmol Vis Sci. 1999;40:2803-9.

55. Ramrattan RS, Wolfs RC, Panda-Jonas S, Jonas JB, Bakker D, Pols HA, et al. Prevalence and causes of visual field loss in the elderly and associations with impairment in daily functioning: the Rotterdam Study. Arch Ophthalmol. 2001;119:1788-94.

56. Hong T, Mitchell P, Burlutsky G, Samarawickrama C, Wang JJ. Visual impairment and the incidence of falls and fractures among older people: longitudinal findings from the Blue Mountains Eye Study. Invest Ophthalmol Vis Sci. 2014;55:7589-93.

57. Freeman EE, Munoz B, Rubin G, West SK. Visual field loss increases the risk of falls in older adults: the Salisbury eye evaluation. Invest Ophthalmol Vis Sci. 2007;48:4445-50.

58. Patino CM, McKean-Cowdin R, Azen SP, Allison JC, Choudhury F, Varma R, et al. Central and peripheral visual impairment and the risk of falls and falls with injury. Ophthalmology. 2010;117:199-206 e1.

59. Coleman AL, Cummings SR, Ensrud KE, Yu F, Gutierrez P, Stone KL, et al. Visual field loss and risk of fractures in older women. J Am Geriatr Soc. 2009;57:1825-32.

60. Lamoureux EL, Chong E, Wang JJ, Saw SM, Aung T, Mitchell $\mathrm{P}$, et al. Visual impairment, causes of vision loss, and falls: the singapore malay eye study. Invest Ophthalmol Vis Sci. 2008;49:528-33.

61. Klein BE, Moss SE, Klein R, Lee KE, Cruickshanks KJ. Associations of visual function with physical outcomes and limitations 5 years later in an older population: The Beaver Dam eye study. Ophthalmology. 2003;110:644-50.

62. Black AA, Wood JM, Lovie-Kitchin JE. Inferior field loss increases rate of falls in older adults with glaucoma. Optom Vis Sci. 2011;88:1275-82.

63. Coleman AL, Cummings SR, Yu F, Kodjebacheva G, Ensrud KE, Gutierrez P, et al. Binocular visual-field loss increases the risk of future falls in older white women. J Am Geriatr Soc. 2007;55:357-64.

64. Sotimehin AE, Yonge AV, Mihailovic A, West SK, Friedman DS, Gitlin LN, et al. Locations, Circumstances, and Outcomes of Falls in Patients With Glaucoma. Am J Ophthalmol. 2018;192:131-41.

65. Bramley T, Peeples P, Walt JG, Juhasz M, Hansen JE. Impact of vision loss on costs and outcomes in medicare beneficiaries with glaucoma. Arch Ophthalmol. 2008;126:849-56.

66. McGwin G Jr, Mays A, Joiner W, Decarlo DK, McNeal S, Owsley C. Is glaucoma associated with motor vehicle collision involvement and driving avoidance? Invest Ophthalmol Vis Sci. 2004;45:3934-9. 
67. Haymes SA, Leblanc RP, Nicolela MT, Chiasson LA, Chauhan BC. Risk of falls and motor vehicle collisions in glaucoma. Invest Ophthalmol Vis Sci. 2007;48:1149-55.

68. Kwon M, Huisingh C, Rhodes LA, McGwin G Jr, Wood JM, Owsley C. Association between Glaucoma and At-fault Motor Vehicle Collision Involvement among Older Drivers: A Population-based Study. Ophthalmology. 2016;123:109-16.

69. Hu PS, Trumble DA, Foley DJ, Eberhard JW, Wallace RB. Crash risks of older drivers: a panel data analysis. Accid Anal Prev. 1998;30:569-81.

70. Tanabe S, Yuki K, Ozeki N, Shiba D, Abe T, Kouyama K, et al. The association between primary open-angle glaucoma and motor vehicle collisions. Invest Ophthalmol Vis Sci. 2011;52:4177-81.

71. van Landingham SW, Hochberg C, Massof RW, Chan E, Friedman DS, Ramulu PY. Driving patterns in older adults with glaucoma. BMC Ophthalmol. 2013;13:4.

72. Ramulu PY, West SK, Munoz B, Jampel HD, Friedman DS. Driving cessation and driving limitation in glaucoma: the Salisbury Eye Evaluation Project. Ophthalmology. 2009;116: 1846-53.

73. Gilhotra JS, Mitchell P, Ivers R, Cumming RG. Impaired vision and other factors associated with driving cessation in the elderly: The Blue Mountains Eye Study. Clin Exp Ophthalmol. 2001;29:104-7.

74. Bhargava JS, Patel B, Foss AJ, Avery AJ, King AJ. Views of glaucoma patients on aspects of their treatment: an assessment of patient preference by conjoint analysis. Invest Ophthalmol Vis Sci. 2006;47:2885-8.

75. Nguyen AM, van Landingham SW, Massof RW, Rubin GS, Ramulu PY. Reading ability and reading engagement in older adults with glaucoma. Invest Ophthalmol Vis Sci. 2014;55:5284-90.

76. Burton R, Saunders LJ, Crabb DP. Areas of the visual field important during reading in patients with glaucoma. Jpn J Ophthalmol. 2015;59:94-102.

77. Glen FC, Crabb DP, Smith ND, Burton R, Garway-Heath DF. Do patients with glaucoma have difficulty recognizing faces? Invest Ophthalmol Vis Sci. 2012;53:3629-37.

78. Zhang X, Olson DJ, Le P, Lin FC, Fleischman D, Davis RM. The Association Between Glaucoma, Anxiety, and Depression in a Large Population. Am J Ophthalmol. 2017;183:37-41.

79. Jung KI, Park CK. Mental Health Status and Quality of Life in Undiagnosed Glaucoma Patients: A Nationwide PopulationBased Study. Medicine (Baltimore). 2016;95:e3523.

80. Lim NC, Fan CH, Yong MK, Wong EP, Yip LW. Assessment of Depression, Anxiety, and Quality of Life in Singaporean Patients With Glaucoma. J Glaucoma. 2016;25:605-12.

81. Su CC, Chen JY, Wang TH, Huang JY, Yang CM, Wang IJ. Risk factors for depressive symptoms in glaucoma patients: a nationwide case-control study. Graefes Arch Clin Exp Ophthalmol. 2015;253:1319-25.

82. Wang SY, Singh K, Lin SC. Prevalence and predictors of depression among participants with glaucoma in a nationally representative population sample. Am J Ophthalmol. 2012;154:436-444 e2.

83. Mabuchi F, Yoshimura K, Kashiwagi K, Shioe K, Yamagata Z, Kanba S, et al. High prevalence of anxiety and depression in patients with primary open-angle glaucoma. J Glaucoma. 2008; 17:552-7.

84. Zhou C, Qian S, Wu P, Qiu C. Anxiety and depression in Chinese patients with glaucoma: sociodemographic, clinical, and self-reported correlates. J Psychosom Res. 2013;75:75-82.

85. Ramulu PY, Mihailovic A, West SK, Gitlin LN, Friedman DS. Predictors of Falls per Step and Falls per Year At and Away From Home in Glaucoma. Am J Ophthalmol. 2019;200:169-78.
86. McKean-Cowdin R, Varma R, Wu J, Hays RD, Azen SP. Los Angeles Latino Eye Study G, Severity of visual field loss and health-related quality of life. Am J Ophthalmol. 2007;143: 1013-23.

87. McKean-Cowdin R, Wang Y, Wu J, Azen SP, Varma R, Los Angeles Latino Eye Study G. Impact of visual field loss on health-related quality of life in glaucoma: the Los Angeles Latino Eye Study. Ophthalmology. 2008;115:941-948 e1.

88. Gutierrez P, Wilson MR, Johnson C, Gordon M, Cioffi GA, Ritch $\mathrm{R}$, et al. Influence of glaucomatous visual field loss on healthrelated quality of life. Arch Ophthalmol. 1997;115:777-84.

89. Che Hamzah J, Burr JM, Ramsay CR, Azuara-Blanco A, Prior M. Choosing appropriate patient-reported outcomes instrument for glaucoma research: a systematic review of vision instruments. Qual Life Res. 2011;20:1141-58.

90. Quaranta L, Riva I, Gerardi C, Oddone F, Floriani I, Konstas AG. Quality of Life in Glaucoma: A Review of the Literature. Adv Ther. 2016;33:959-81.

91. Vandenbroeck S, De Geest S, Zeyen T, Stalmans I, Dobbels F. Patient-reported outcomes (PRO's) in glaucoma: a systematic review. Eye (Lond). 2011;25:555-77.

92. Dempster M, McCorry NK, Donnelly M, Barton K, AzuaraBlanco A. Individualisation of glaucoma quality of life measures: a way forward? Br J Ophthalmol. 2019;103:293-5.

93. Nelson P, Aspinall P, Papasouliotis O, Worton B, O'Brien C. Quality of life in glaucoma and its relationship with visual function. J Glaucoma. 2003;12:139-50.

94. Medeiros FA, Gracitelli CP, Boer ER, Weinreb RN, Zangwill LM, Rosen PN. Longitudinal changes in quality of life and rates of progressive visual field loss in glaucoma patients. Ophthalmology. 2015;122:293-301.

95. Abe RY, Diniz-Filho A, Costa VP, Gracitelli CP, Baig S, Medeiros FA. The Impact of Location of Progressive Visual Field Loss on Longitudinal Changes in Quality of Life of Patients with Glaucoma. Ophthalmology. 2016;123:552-7.

96. Odberg T. Visual field prognosis in advanced glaucoma. Acta Ophthalmol. 1987;65(suppl):27-29.

97. Grant WM, Burke JF Jr. Why do some people go blind from glaucoma? Ophthalmology. 1982;89:991-8.

98. Wilson R, Walker AM, Dueker DK, Crick RP. Risk factors for rate of progression of glaucomatous visual field loss: a computerbased analysis. Arch Ophthalmol. 1982;100:737-41.

99. Mikelberg FS, Schulzer M, Drance SM, Lau W. The rate of progression of scotomas in glaucoma. Am $\mathrm{J}$ Ophthalmol. 1986;101:1-6.

100. Lee JM, Caprioli J, Nouri-Mahdavi K, Afifi AA, Morales E, Ramanathan $\mathrm{M}$, et al. Baseline prognostic factors predict rapid visual field deterioration in glaucoma. Invest Ophthalmol Vis Sci. 2014;55:2228-36.

101. Oliver JE, Hattenhauer MG, Herman D, Hodge DO, Kennedy R, Fang-Yen M, et al. Blindness and glaucoma: a comparison of patients progressing to blindness from glaucoma with patients maintaining vision. Am J Ophthalmol. 2002;133:764-72.

102. Mokhles P, Schouten JS, Beckers HJ, Azuara-Blanco A, Tuulonen A, Webers CA. A Systematic Review of End-of-Life Visual Impairment in Open-Angle Glaucoma: An Epidemiological Autopsy. J Glaucoma. 2016;25:623-8.

103. Goh YW, Ang GS, Azuara-Blanco A. Lifetime visual prognosis of patients with glaucoma. Clin Experiment Ophthalmol. 2011;39:766-70.

104. Ernest PJ, Busch MJ, Webers CA, Beckers HJ, Hendrikse F, Prins $\mathrm{MH}$, et al. Prevalence of end-of-life visual impairment in patients followed for glaucoma. Acta Ophthalmol. 2013;91:738-43.

105. Hattenhauer MG, Johnson DH, Ing HH, Herman DC, Hodge DO, Yawn BP, et al. The probability of blindness from openangle glaucoma. Ophthalmology. 1998;105:2099-104. 
106. Mokhles P, Schouten JS, Beckers HJ, Azuara-Blanco A, Tuulonen A, Webers CA. Glaucoma blindness at the end of life. Acta Ophthalmol. 2017;95:10-11.

107. Forsman E, Kivela T, Vesti E. Lifetime visual disability in openangle glaucoma and ocular hypertension. $\mathrm{J}$ Glaucoma. 2007;16:313-9.

108. Ang GS, Eke T. Lifetime visual prognosis for patients with primary open-angle glaucoma. Eye (Lond). 2007;21: 604-8.

109. Griffith JF, Goldberg JL. Prevalence of comorbid retinal disease in patients with glaucoma at an academic medical center. Clin Ophthalmol. 2015;9:1275-84.

110. Kolar P. Risk factors for central and branch retinal vein occlusion: a meta-analysis of published clinical data. J Ophthalmol. 2014;2014:724780.

111. Yin X, Li J, Zhang B, Lu P. Association of glaucoma with risk of retinal vein occlusion: A meta-analysis. Acta Ophthalmol. 2019;97:652-9.

112. Rahman MQ, Beard SM, Discombe R, Sharma R, Montgomery DM. Direct healthcare costs of glaucoma treatment. Br J Ophthalmol. 2013;97:720-4.

113. Grodum K, Heijl A, Bengtsson B. Glaucoma and mortality. Graefes Arch Clin Exp Ophthalmol. 2004;242:397-401.

114. Peters D, Bengtsson B, Heijl A. Lifetime risk of blindness in open-angle glaucoma. Am J Ophthalmol. 2013;156:724-30.

115. Garway-Heath DF, Crabb DP, Bunce C, Lascaratos G, Amalfitano F, Anand N, et al. Latanoprost for open-angle glaucoma (UKGTS): a randomised, multicentre, placebo-controlled trial. Lancet. 2015;385:1295-304.

116. The AGIS Investigators. The Advanced Glaucoma Intervention Study (AGIS): 7. The relationship between control of intraocular pressure and visual field deterioration. Am J Ophthalmol. 2000;130:429-40.

117. Maier PC, Funk J, Schwarzer G, Antes G, Falck-Ytter YT. Treatment of ocular hypertension and open angle glaucoma: meta-analysis of randomised controlled trials. BMJ. 2005; 331:134.

118. The Collaborative Normal-Tension Glaucoma Study Group. Comparison of glaucomatous progression between untreated patients with normal-tension glaucoma and patients with therapeutically reduced intraocular pressures. Am J Ophthalmol. 1998;126:487-97.

119. Lichter PR, Musch DC, Gillespie BW, Guire KE, Janz NK, Wren PA, et al. Interim clinical outcomes in the Collaborative Initial Glaucoma Treatment Study comparing initial treatment randomized to medications or surgery. Ophthalmology. 2001;108:1943-53.

120. Gordon MO, Beiser JA, Brandt JD, Heuer DK, Higginbotham EJ, Johnson CA, et al. The Ocular Hypertension Treatment Study: baseline factors that predict the onset of primary openangle glaucoma. Arch Ophthalmol. 2002;120:714-20. discussion 829-30

121. Ederer F, Gaasterland DE, Sullivan EK. The Advanced Glaucoma Intervention Study (AGIS): 1. Study design and methods and baseline characteristics of study patients. Control Clin Trials. 1994;15:299-325.

122. Greenrod EB, Jones MNA, Kaye S, Larkin DFP. Center and surgeon effect on outcomes of endothelial keratoplasty versus penetrating keratoplasty in the United Kingdom. American Journal of Ophthalmology. 2014;158:957-66.

123. Gedde SJ, Schiffman JC, Feuer WJ, Parrish RK 2nd, Heuer DK, Brandt JD, et al. The tube versus trabeculectomy study: design and baseline characteristics of study patients. Am J Ophthalmol. 2005; 140:275-87.

124. Gedde SJ, Feuer WJ, Shi W, Lim KS, Barton K, Goyal S, et al. Treatment Outcomes in the Primary Tube Versus
Trabeculectomy Study after 1 Year of Follow-up. Ophthalmology. 2018;125:650-63.

125. Kirwan JF, Lockwood AJ, Shah P, Macleod A, Broadway DC, King AJ, et al. Trabeculectomy in the 21 st century: a multicenter analysis. Ophthalmology. 2013;120:2532-9.

126. Stead RE, King AJ. Outcome of trabeculectomy with mitomycin $\mathrm{C}$ in patients with advanced glaucoma. $\mathrm{Br} \mathrm{J}$ Ophthalmol. 2011;95:960-5.

127. Burr J, Azuara-Blanco A, Avenell A, Tuulonen A. Medical versus surgical interventions for open angle glaucoma. Cochrane Database of Systematic Reviews, 2012: https://doi.org/10.1002/ 14651858.CD004399.pub3.

128. Smith R. A comparison between medical and surgical treatment of glaucoma simplex-results of a prospective study. Trans Ophthalmol Soc Aust. 1968;27:17-29.

129. Migdal C, Gregory W, Hitchings R, Kolker AE. Long-term functional outcome after early surgery compared with laser and medicine in open-angle glaucoma. Ophthalmology. 1994;101:1651-7.

130. Jay JL, Murray SB. Early trabeculectomy versus conventional management in primary open angle glaucoma. Br J Ophthalmol. 1988;72:881-9.

131. The European Glaucoma Society. Terminology and Guidelines for Glaucoma. 4th ed. 2014, Italy.

132. Prum BE Jr, Rosenberg LF, Gedde SJ, Mansberger SL, Stein JD, Moroi SE, et al. Primary Open-Angle Glaucoma Preferred Practice Pattern Guidelines. Ophthalmology. 2016;123:P41-p111.

133. Stead R, Azuara-Blanco A, King AJ. Attitudes of consultant ophthalmologists in the UK to initial management of glaucoma patients presenting with severe visual field loss: a national survey. Clin Experiment Ophthalmol. 2011;39:858-64.

134. Moster MR, Moster ML. Wipe-out: a complication of glaucoma surgery or just a blast from the past? Am J Ophthalmol. 2005;140:705-6.

135. Law SK, Nguyen AM, Coleman AL, Caprioli J. Severe loss of central vision in patients with advanced glaucoma undergoing trabeculectomy. Arch Ophthalmol. 2007;125:1044-50.

136. Costa VP, Smith M, Spaeth GL, Gandham S, Markovitz B. Loss of visual acuity after trabeculectomy. Ophthalmology. 1993;100:599-612.

137. Balekudaru S, George R, Panday M, Singh M, Neog A, Lingam V. Prospective evaluation of early visual loss following glaucoma-filtering surgery in eyes with split fixation. J Glaucoma. 2014;23:211-8.

138. Topouzis F, Tranos P, Koskosas A, Pappas T, Anastasopoulos E, Dimitrakos S, et al. Risk of sudden visual loss following filtration surgery in end-stage glaucoma. Am J Ophthalmol. 2005;140:661-6.

139. Guedes RA, Guedes VM, Freitas SM, Chaoubah A. Quality of life of medically versus surgically treated glaucoma patients. J Glaucoma. 2013;22:369-73.

140. Varma R, Lee PP, Goldberg I, Kotak S. An assessment of the health and economic burdens of glaucoma. Am J Ophthalmol. 2011;152:515-22.

141. Rouland JF, Berdeaux G, Lafuma A. The economic burden of glaucoma and ocular hypertension: implications for patient management: a review. Drugs Aging. 2005;22:315-21.

142. Traverso CE, Walt JG, Kelly SP, Hommer AH, Bron AM, Denis $P$, et al. Direct costs of glaucoma and severity of the disease: a multinational long term study of resource utilisation in Europe. Br J Ophthalmol. 2005;89:1245-9.

143. Bunce C, Xing W, Wormald R. Causes of blind and partial sight certifications in England and Wales: April 2007-March 2008. Eye (Lond). 2010;24:1692-9.

144. Pezzullo L, Streatfeild J, Simkiss P, Shickle D. The economic impact of sight loss and blindness in the UK adult population. BMC Health Serv Res. 2018;18:63. 
145. Chakravarthy U, Biundo E, Saka RO, Fasser C, Bourne R, Little JA. The Economic Impact of Blindness in Europe. Ophthalmic Epidemiol. 2017;24:239-47.

146. Meads C, Hyde C. What is the cost of blindness? Br J Ophthalmol. 2003;87:1201-4.

147. Thygesen J, Aagren M, Arnavielle S, Bron A, Frohlich SJ, Baggesen $\mathrm{K}$, et al. Late-stage, primary open-angle glaucoma in Europe: social and health care maintenance costs and quality of life of patients from 4 countries. Curr Med Res Opin. 2008;24:1763-70.

148. Department of Health. Improving outcomes and supporting transparency in Public Health Outcomes Framework. 2012, London.

149. King AJ, Stead RE, Rotchford AP. Treating patients presenting with advanced glaucoma - should we reconsider current practice? Br J Ophthalmol. 2011;95:1185-92. 